\title{
Rethinking Community Within the Context of Social Inclusion as Social Justice: Implications for Women After Federal Incarceration
}

\author{
DARLA FORTUNE \\ University of Waterloo, Canada \\ SUSAN M. ARAI \\ University of Waterloo, Canada
}

\begin{abstract}
Very little is known about how women's experiences with inclusion or exclusion shape their entry into community after they have been incarcerated. Thus, the purpose of this study was to examine inclusion from the perspective of women entering community after release from a federal prison in Ontario, Canada. This research project combined feminist participatory action research with anti-oppressive theories. Women who had been incarcerated were asked to come together to discuss ideas around inclusion and explore ways to foster a more inclusive environment. As women described the kind of community they experienced before and after incarceration, themes of being pushed out of community, being pulled into community, and negotiating issues of responsibility were evident. At the core of these themes was a powerful sense of difference. Findings suggest that deep societal change is needed for women to truly experience social inclusion upon their release from federal prison. They also suggest a role for community in supporting personal change and growth. We argue that if principles of social justice guided inclusion efforts, there would be dialogue and negotiation aimed at re-imagining social inclusion and creating a space that is hopeful and inclusive for all citizens.
\end{abstract}

\section{Introduction}

There have been times in recent history when Canadians have expressed a desire to become more caring, accepting, and socially just members of society. One example of such expression was our collective reaction to a 
message delivered to Canadians by Jack Layton, the former leader of the federal New Democratic Party and official leader of the opposition to Canada's Conservative government. Prior to his death in August 2011, Layton expressed these sentiments:

Love is better than anger. Hope is better than fear. Optimism is better than despair. So let us be loving, hopeful and optimistic. And we'll change the world. (Layton, 2011)

In the days and weeks that followed his death, Layton's words went viral on social media sites around the country and triggered an outpouring of emotion. Canadians were clearly moved and personally inspired by his message of shared hope and optimism for a better future.

Public support for the ideals of shared hope and optimism are particularly reassuring when we consider their implications for women who worked with the first author of this paper on a participatory research project aimed at critically examining social inclusion for women who enter community after federal incarceration. This study was guided by an anti-oppressive theoretical framework. As Moosa-Mitha (2005a) explained, anti-oppressive researchers adopt a difference-centered stance by recognizing that oppression is based on multiple differences. Research guided by anti-oppressive theories strives to expose dominant constructions of reality by questioning normative structures that serve the interests of a particular class, namely, those who are included. As Salojee (2005) argued:

The intersection of an anti-oppression discourse with social inclusion as process and outcome is an incredibly powerful impetus to social change and political solidarity. It presents a radical alternative to the dominant discourse that is steeped in liberal notions of formal equality. (p.201)

During this study critical attention was given to inclusionary practices that encourage women to fit into normative structures within society. Consideration was also given to the relevance of liberal theories that do not challenge normative practices and assumptions (Moosa-Mitha, 2005a). For this study women were invited to engage in dialogue intended to re-imagine what social inclusion might look like if we moved away from adopting the dominant discourse on inclusion and take a more difference-centered approach.

This study was designed as a feminist participatory action research (FPAR) project. FPAR centers gender and women's experiences while challenging forms of patriarchy, transforming power relations, and promoting social change (Reid \& Frisby, 2008). Using FPAR to explore how issues of difference and oppression shape social inclusion helped to critically reimagine social inclusion for women whose relationships and aspirations are often different from the assumed norm. Since inclusion and participation are central to FPAR (Frisby, Reid, Millar \& Hoeber, 2005), this approach was appropriate for a study about social inclusion and responded to Lister's (2000) call for strategies aimed at inclusion to be inclusive also in their development and implementation. This project sought to not only understand 
the nature of social inclusion from the perspective of women who have entered community but also to encourage their involvement in creating a more inclusive environment.

Conducting FPAR from an anti-oppressive perspective can help deepen our understanding of how issues of difference shape inclusion efforts. It also reveals the need for societal change if women are going to truly experience social inclusion upon their release from federal prison. Similar to the work of other researchers (e.g., Hall, 2005; Reid, 2004), this study revealed a strong connection between social inclusion and social justice. As much as this study was concerned with social inclusion, it was also grounded in social justice and the belief that moving toward a socially just society is integral to our collective well-being.

Canadians may be ready to embrace a sense of shared optimism for a better future but are we also willing to acknowledge our shared responsibility for addressing social inequality and fostering conditions of hope? In particular, as it relates to this research project, are we willing to share the responsibility for fostering a hopeful space in community where women leaving federal prison can feel included and supported?

There is a long-standing but tenuous connection between the idea of shared responsibility and the future of women who are federally incarcerated in Canada. The idea of shared responsibility was identified over twenty years ago as a key principle that ought to guide women's corrections in Canada. In 1990 the Task Force on Federally Sentenced Women (TFFSW) released a report called Creating Choices which proposed a new women-centered model of corrections based on the belief that women's successful reintegration into community has to be grounded in shared responsibility. As stated in the report:

The holistic programming and multifaceted opportunities which support an environment in which women can become empowered can only be built on a foundation of responsibility among a broad range of community members. Currently, because the Correctional Service of Canada has legal obligations for federally sentenced women, responsibility for federal women is too narrowly assigned to correctional systems. (TFFSW, 1990, p. 111)

The principle of shared responsibility emphasizes a role for the federal correctional system, the government, and community when it comes to fostering conditions that support women's empowerment. This principle not only responds to the charge that responsibility has traditionally been too narrowly assigned to correctional systems; it also addresses a lack of responsibility taken by the larger society which accepts and nurtures social conditions that produce criminal activity. The idea of collective or shared responsibility for crime and for individuals who commit crime necessitates a more inclusive and socially just society.

The purpose of this paper is two-fold. First, by sharing the insights and experiences of women who participated in the research, we show how their experiences of community before and after they were incarcerated can be 
compared and contrasted with the caring, accepting, and socially just society we seem to desire. Second, by keeping social justice at the forefront of discussions on inclusion, we argue that inclusion as a measure of social justice has to be more than a matter of self-determination and personal responsibility; it has to move toward shared responsibility and a shift to mutuality if there is to be any hope and optimism for a better world. Underlying this purpose is the idea that at the centre of exclusion and social injustice is often a powerful sense of difference.

Bell (1997) explained that social justice holds to a vision in which individuals are both self-determining and interdependent while there is a sense of social responsibility aimed at addressing social inequities. Bach and Rioux (1996) described the connection between individual and social well-being when they explained that "individuals cannot attain well-being by themselves. They do so in the context of the communities in which they belong" (p. 71). Individual well-being is enhanced when communities provide the social, economic, cultural, and environmental context for supporting the well-being of its diverse members (Wilkinson \& Marmot, 2003).

Despite our apparent desire for a caring, accepting, and socially just society and despite proposed philosophical changes to women's corrections connected to notions of social justice, tensions exist when it comes to embracing notions of shared responsibility for women who have entered our federal justice system. One such tension can be seen in the passing of Bill C-10 by Canada's Conservative government in March 2012. Commonly referred to as the Omnibus Crime Bill, Bill C-10 groups together nine bills that strongly endorse a get-tough-on-crime agenda. Aspects of Bill-C which most impact women are the increases to mandatory minimum sentences for certain minor and non-violent offenses (Barnett, Dupuis, Kirkby et al., 2012) and the accompanying loss of judges' discretionary power. As Himelfarb (2011) explains, when judges' discretion is compromised it is difficult for them to fit the penalty to the circumstances by addressing aggravating and mitigating factors to crime. Changes called for in Bill C-10 are believed to unfairly target women who are arguably already among the most susceptible to inequitable treatment in the justice system (Giroday, 2011).

There is a fundamental contradiction between notions of shared hope and responsibility and our seemingly unrelenting resolve to punish people who have broken the law. Similar contradictions were inherent in this research when women involved in the project grappled with issues of responsibility during discussions around social inclusion. To give context to the insights and experiences women shared regarding inclusion in community, we will first explore the idea of social inclusion as social justice.

\section{Social Inclusion as Social Justice}

Efforts to create more socially inclusive communities have been receiving greater attention in recent years and it has been argued that for social inclusion 
to be a reality, all members of society should be able to participate as valued, respected, and contributing citizens (Laidlaw Foundation, 2002). From an anti-oppressive perspective, experiences of inclusion and exclusion are often a result of normative social beliefs that construct difference as inferior (Moosa-Mitha, 2005a). Social inclusion as social justice is primarily about addressing issues of power and difference (Shakir, 2005). Of importance here is what is required to shift if inclusion is to occur for women entering community after incarceration.

The challenge of opposing exclusion is the risk of assimilation if the inherently inequitable and unmovable centre does not change (Labonte, 2004; Lister, 2000). Shakir (2005) argued that "the problem with social inclusion discourse in Canada is that it has integration of the margin into the centre as its desirable end" (p. 212). There is a similar "desirable end" being advanced in literature pertaining to the reintegration and social inclusion of women entering community from prison. For example, Uggen, Manza, and Behrens (2004) suggested that reintegration and social inclusion efforts will be enhanced and the stigma of incarceration minimized if offenders are able to adopt a pro-social identity upon release from prison. Pro-social identities are considered to occur when offenders become productive, responsible, and active citizens in the work, family, and community domains. In this sense, social inclusion is linked to becoming a "productive citizen at work, a responsible citizen at home, and an active citizen in the community" (Uggen et al., p. 263). Thus, encouraging the pro-social behaviour of offenders is not unlike encouraging assimilation into the centre (Shakir).

Linking pro-social behaviour to inclusion for women entering community from prison is problematic on several levels. For example, it is naive to assume that women will automatically feel a sense of community responsibility upon release from prison since, like many women in our society, they were apt to live in communities that were male-dominated, often inescapable, and void of opportunities for women to resist oppressive social roles (Frazer \& Lacey, 1993). Further, a woman's path to incarceration is often paved with issues such as abuse, poverty, inadequate education, and drug abuse (Pedlar, Arai, Yuen, \& Fortune, 2008; Pollack, 2008; Richie, 2001). Thus, it can be argued that the inability of communities to tackle these systemic issues results in the marginalization and desperation of vulnerable individuals. Why would women marginalized by community structures automatically place a high priority on becoming active community citizens?

It is also difficult to believe that power relations present in community can support women trying to achieve a meaningful level of productivity after incarceration. Stigma associated with a prison sentence often limits participation in community life and detracts from civic reintegration (Uggen et al., 2004). Porter (2000) argued that social exclusion is a gendered term which rests on norms associating inclusion with the male sphere of production. Gendered processes, such as the consideration of paid work as work and the neglect of domestic work, are central to the idea that women are more susceptible to social exclusion (Jackson, 1999). 
Women, already at a disadvantage in terms of being included through paid employment, are at an even greater disadvantage if they have spent time in prison (Pedlar et al., 2008; Pollack, 2008). Unemployment and subsequent poverty is a shared reality for many incarcerated women (Faith, 2006; Richie, 2001). Prospects for social inclusion are further diminished when women in prison are portrayed as evil, aggressive, and pathological outcasts and are subsequently denied opportunities to exercise their capacity as contributing citizens (Pedlar, Arai, \& Yuen, 2007). Stigma is even more pronounced if the woman who has offended is a mother and the marginalization that ensues from having committed a crime is deepened when the idea of motherhood comes with normative cultural expectations associated with being wholesome and responsible (Pedlar et al., 2008).

When theories of civic reintegration and the adoption of pro-social identities are privileged in the reintegration literature, insufficient attention is given to systemic issues of inequality, control, and oppression as explored by feminist researchers, indigenous scholars, and critical race theorists. Radosh (2002), for example, explained that female offenders have been victimized through multiple stages of patriarchy when she stated, "structure, oppression, economic exploitation, and marginalized social opportunity explain almost all of women's crime" (p. 303). Where notions of pro-social identities suggest the only way women can achieve social inclusion is by conforming to dominant social norms, this literature overlooks how women's agency and efforts to resist oppression may foster their social inclusion.

To achieve an understanding of social inclusion that is socially just, it is necessary to consider that both structural determinants and individual agency lie at the heart of inclusion processes (Dominelli, 2005; Lister, 2000). Definitions of inclusion that emphasize personal agency consider "how individuals transcend structural limitations to create resources that promote inclusivity" (Dominelli, 2005, p. 16). However, if efforts at inclusion ignore the ideological, material, and political structures that unequally benefit some and disadvantage others, there is the risk of assimilation whereby the agency of those who are less powerful becomes assimilated by the mainstream (Lister, 2000). Increasing attention has been given to ways structural dimensions shape the inclusion process (Shookner, 2002). For example, efforts to enhance inclusion have started to address social issues such as poverty with an aim to reducing barriers that limit access to employment, education, and other material resources (Mitchell \& Shillington, 2005). When social inclusion efforts involve respect for difference and removal of barriers to participate in public life (Salojee, 2005), we see the beginning of a movement toward social justice.

There are many definitions of social inclusion and exclusion. They are considered multi-dimensional since disadvantage takes place in a variety of domains (Mitchell \& Shillington, 2005). For example, Salojee (2005) noted social inclusion:

is about social cohesion plus, it is about citizenship plus, it is about the removal of barriers plus, it is anti-essentialist plus, it is about rights and responsibilities 
plus, it is about accommodation of differences plus, it is about democracy plus, and it is about a new way of thinking about the problems of injustice, inequalities and exclusion plus. (p. 198)

Multi-dimensional understandings of social inclusion, such as Salojee's are often rooted in classic liberal theory and a focus on issues of citizenship, rights, and responsibilities which is often criticized for presenting culturally specific social relations as universal norms and encouraging assimilation under the guise of integration (Luxton, 2005). Therefore, there is a need to examine social inclusion from other perspectives using methodologies which allow for voice and difference to be honoured while countering prevailing ideologies and power relations. Such goals are central to anti-oppressive (Moosa-Mitha, 2005b) and feminist participatory action research (Reid \& Frisby, 2008) approaches. A gendered and anti-oppressive analysis of social inclusion can move us away from paternal policy options that fail to challenge existing power imbalances and obstruct the creation of any real change (Shakir, 2005).

\section{Methodology}

The overall purpose of this study was to examine social inclusion from the perspective of women who entered community after release from federal prison. The project employed the tenets of anti-oppressive research (AOR). Combining FPAR with AOR helped to ensure that research being conducted was both critical and difference-centered. This approach was particularly useful for examining discourse that privileges normative assumptions about social inclusion because it promotes the idea that knowledge is owned by and belongs to groups experiencing marginalization (Moosa-Mitha, 2005b; Potts \& Brown, 2005).

Following Hall's (2005) argument that negotiating the discourse of inclusion and exclusion requires a critical re-imagining of inclusion as social justice, women who participated in this study were engaged in dialogue aimed at re-imagining what inclusion means for women entering community after incarceration. In keeping with the participatory nature of this study, there was an emphasis on the value of collaborative learning. Thus, rather than adhering to a rigid research design, the project unfolded over time and was influenced by the decisions of women who participated and the knowledge exchange that occurred.

Women who had been federally incarcerated at Grand Valley Institution (GVI) in Kitchener, Ontario and who were living in the Waterloo region were invited to form a research group to explore alternate ways to conceptualize inclusion that would help foster a more inclusive environment for women entering community after their release from prison. Nine women participated at various stages of the project. Four women who responded to the initial recruitment letter formed a research group and held seven meetings throughout the first phase of the study. 
Although the research project was still in its formative stage, when the group held its seventh meeting only one woman was still interested and able to participate in the project. Other members of the group, for different reasons that were all personal in nature, were no longer able to participate. At this time the research group disbanded. Shortly before disbanding, the group discussed ways to collect and represent the data by considering the group's strengths and interests and what methods would be complementary. Photovoice was identified as a viable method and disposable cameras were distributed to each woman.

Photovoice has three goals (MacDonald, Sarche, \& Wang, 2005) that complement the aims of this research project. First, it enables participants to record and reflect on their personal and community strengths and concerns. Second, it promotes critical dialogue and knowledge about personal and community issues through group discussion of photographs. Third, photovoice is often intended to reach and touch policy makers, which was an explicit goal identified by women who participated in the first phase of the study.

Photovoice provides researchers with an opportunity to see the world from the view of participants and it provides participants with the opportunity to describe what their photos mean and reflect on their meaning (Wang \& Burris, 1997). Members of the research group were asked to take pictures of people, places, and things in the community that contributed to feeling either like they belonged or did not belong. They expressed excitement about this particular method and identified the potential for photovoice to be a vehicle for changing public perceptions about women who had spent time in prison. In one of the group's last meetings, women shared and spoke about the pictures they had taken. These pictures powerfully demonstrated women's experiences with inclusion and exclusion upon entering community, and, as they described their pictures, the stories of these experiences were further brought to light.

When women who participated in phase one left the project, attention was directed toward honouring the decisions that had been made regarding the use of photovoice. Therefore, with the help of one remaining research group member, additional women were recruited to participate in the project and invited to engage in photovoice. Five additional women participated in this second phase of the project which also involved the use of photovoice. Conversational interviews were then conducted with each woman about the pictures she had taken. Throughout this phase the first author continued to connect with women who participated in the first phase of the project. Follow-up interviews with women who were part of the research group shed additional light on their experiences of inclusion and exclusion in the community. In each phase of the study there were opportunities for women to share, through group discussion and personal interviews, their insights and experiences relating to social inclusion after federal incarceration.

Women who participated in this study ranged in age from early twenties to early fifties. The range of time since being released from GVI was between 
two months and two-and-a-half years. Seven women were white and two women were black. Seven women indicated that they had drug and alcohol addictions and that their incarceration was directly related to their addictions. Women differed with respect to sexual orientation and at the time of the study one woman was married, one woman was engaged, and all other women were either single or in casual relationships. Four women were mothers, but only one had dependent children at the time of the study. There were variations in employment status, with one woman working a part-time job while going to university, one woman temporarily laid off from a seasonal job, one woman who had just finished employment through a summer grant, one woman starting a part-time at-home business, and other women choosing to work on their addiction recovery before searching for employment. There were also variations in education levels. One woman was a full-time university student, one woman was taking university courses through correspondence and had been accepted into full-time studies in the fall, and one woman was taking courses in preparation for university. Several other women spoke about taking their General Educational Development (GED) test while in GVI.

Women who participated in this study were similar to other women leaving federal prison when it came to addiction issues. As stated above, seven out of nine women indicated that they had drug and alcohol addictions. This compares with other studies that acknowledged a high proportion of women in federal prisons were there because of drug related offenses (Pedlar et al., 2008; Taylor and Flight, 2004). Women in this study varied from the profile of women who have been federally incarcerated in terms of education and employment levels since most had higher levels of education and lower employment-related needs than what is commonly reported (cf. Pedlar et al., 2008; Pollack, 2008).

\section{Insights about social inclusion after federal incarceration}

Data presented in this paper came from conversations during research group meetings, conversations with women who had engaged with photovoice, and individual interviews with women in follow-up from their participation in the research group. Throughout each phase of data collection, women offered insight into the contested nature of community and how idealized and normative it could be at times. This ideal was compared to and contrasted with the kind of community women experienced before and after a period of incarceration. Women described times when they felt they were being pushed out of community and times when they were being pulled into community. They also highlighted tensions around the necessary supports and resources for personal change and growth as they negotiated issues of responsibility. The central themes in this study, being pushed out of community; being pulled into community; and negotiating issues of responsibility pertaining to social inclusion, reveal the ambiguous nature of social inclusion for women who have broken the law and raise critical questions about social justice. 


\section{Being pushed out of Community: Vulnerability to Exclusion and Stigma}

This theme highlights complexities associated with seeking to belong while faced with insufficient supports and resources, threats to independence, and feelings related to difference and stigma. At first glance, idealized notions of community may seem to offset this complexity, suggesting that as women become part of a community they will share in its promise of inclusivity and belonging. However, it has been argued that the ideal of community, offered as a response to prevailing conditions associated with alienation and fragmentation, provides a totalizing perspective of community that denies difference (Young, 1989). Experiences and perceptions shared by women in this study are in accordance with this difference-denying culture.

Exclusion, in the form of being pushed out, was experienced by women in several aspects of their lives and impacted the extent to which they could relate to notions of the community ideal. For all nine women, the ultimate form of exclusion was being sent to prison. Each woman who participated in this project identified with being pushed out of community when they were removed from their communities and subsequently incarcerated in a women's federal prison.

Exclusion was most evident when women invoked notions of the ideal community and its attendant promises. The promise of community, as described by Bauman (2001), holds that when we belong to a community we can count on each other's good will. At times women spoke as though they believed that when they entered community after incarceration they would receive the help and support they needed from community members and organizations to enable them to be included. Missie, for example, explained that if there were sufficient resources in place for women entering community after incarceration they might start to feel like they were being included upon release:

(Lack of) housing has made me not feel included in the community. I feel I am being discriminated against because of my record. If I had more help from the community, from the resources available to help you be part of the community, then I would feel like I belonged. (Missie)

For women in this study, being pushed out of community started long before they went to prison and persisted after they were released. This theme highlights challenges for women who did not consider themselves to be part of mainstream society because their experiences with poverty, addictions, and incarceration precluded them from measuring up to a normative ideal. Lucy described this normative ideal as having a family, money, social support, and good health:

Sometimes I feel like I don't belong in society because of my past, because I don't have family, because I don't have money, because I don't have proper support, because I'm a drug addict, because of my health. (Lucy) 
During one of our conversations Missie posed and reflected on the following question: "Where do we fit into society when we get out of prison?" This question not only gets to the core of this theme; it gets to the heart of the study. Some women in this study had a history of poverty and addiction which presented challenges in terms of fitting into society. These challenges often led them to withdraw from society and not participate in conventional ways. Liz contrasted people she considers to be part of normal society with people who have addictions based on the ability to participate in society:

Because most of society aren't addicts. Most of society are normal, working people with children and they're working or going to school or whatever. They're participating. They participate in life. So part of being normal is participating.

When you're an addict, you're not participating in society. (Liz)

Tina emphasized the difficulty associated with being included in a society when there are scarce resources available for women after incarceration. She stated: "Being incarcerated for a long period of time, people have a very hard time living in society. Trying to live on what society wants you to live on is hard" (Tina). To illustrate her point, Tina took several pictures (see Figure 1) capturing the extra assistance she required just to obtain such basic necessities as food and clothing:
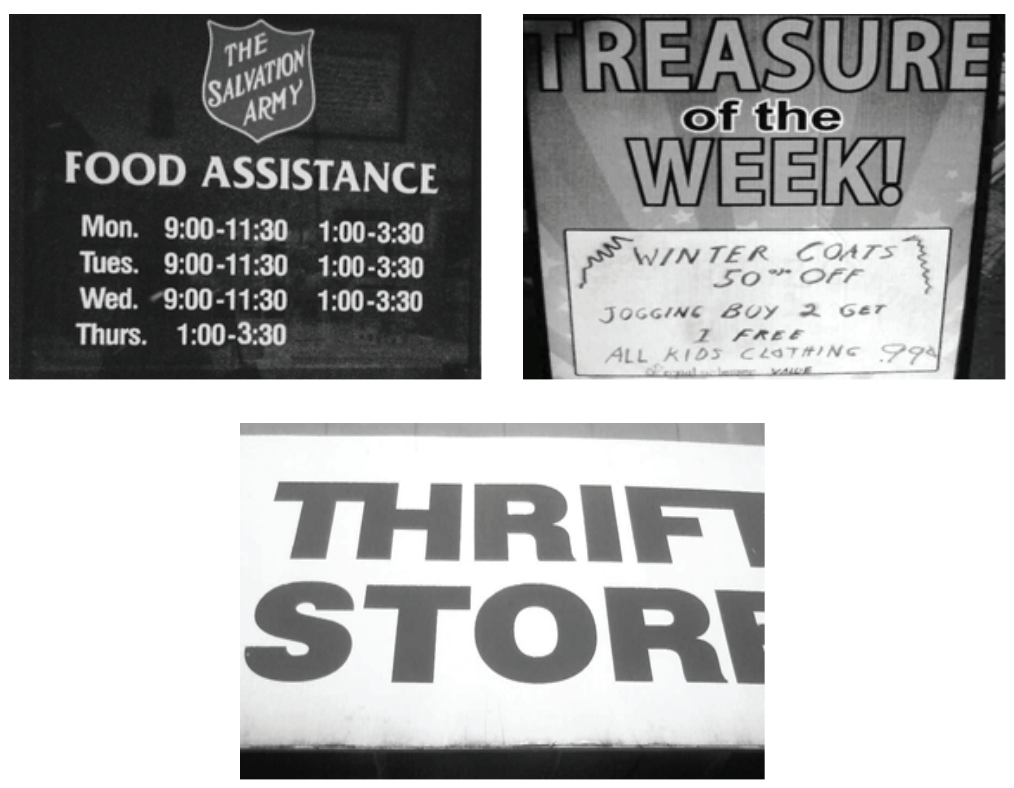

Figure 1

Missie further emphasized pressures women experience as they try to get established in community when resources are scarce and there is the added stress of trying to provide for children: 
I've only been living here for a month and I don't want to go to my landlord and tell him that I can't afford the place. So I joined the food bank. I paid \$9/month so you can go through the food bank store. It's good to a point but they only have certain things. I don't want my kids to feel like they're going to live with mom so they can't have fresh fruit anymore. (Missie)

The financial stress of providing for children that Missie describes above is an example of an exclusionary factor that impacts women leaving prison to a greater extent than men since mothers in prison are far more likely than fathers to be in the primary caregiving role before and after incarceration (Siegel, 2011).

Christie discussed the need for improved resources to be available to women after they leave prison. As she explained, there is unlikely to be positive change for women who return to an unhealthy environment without any transformation in circumstances:

If I could change one thing I would change the resources that are available for establishing a new normal for everyday living. I'm not the only one who's seen women get out of prison and go right back to the environment that was unhealthy, unsafe, and problematic in the first place. How can someone change their life if they go right back to the same neighbourhood, the same friends, abuse, addictions? For a person to change their life, they need to have a change of fundamental circumstances. (Christie)

It has been argued that the contested nature of community and its push toward shared identity and common values has a tendency to repress difference and exclude those who do not share in its commonality (Young, 1990). The exclusionary consequences of desiring community can be seen in descriptions of women's experiences. Women described being excluded not only because of scarce resources, but also because they were not participating in the types of activities they considered to be the norm and because they did not have access to the same standard of living enjoyed by other members of the community. Two commonly recognized indicators of exclusion, lack of participation in mainstream activities and deprivation of resources associated with an accepted standard of living (Taket et al., 2009), reveal the normative aspects of inclusion. Practices of exclusion disproportionately impact people who are unemployed, poorly educated, homeless, single parents, as well as people with disabilities, addictions, and criminal records (Rose, 2000; Taket et al., 2009). These practices cause one to question whether the ideal of community creates any room for difference. Rather, as women involved in this research project describe, difference can too easily be perceived as a problem and lead to experiences of stigmatization.

\section{Stigma of incarceration}

Women often described being pushed out of community because of the enduring stigma of incarceration. Karen explained that a lot of fear is attached 
to trying to find a job when women perceive they are being stigmatized because of their past: "There are just so many fears. When you've been in for a long time and you come out there's the fear of looking for a job, fear of people looking down on you." Feeling stigmatized also has a detrimental effect on sense of belonging. Missie described how women believe they are perceived by society can influence the extent to which they can belong in community. After moving from a place deemed unlivable to a place she considered to be upscale and located in a nice community, Missie explained, "I never thought I belonged in a nice community like this". When asked why she felt this way Missie clarified:

Because of the lifestyle that I'm used to, getting out of prison, still being on parole, not having a lot of money, not having my kids. I wasn't very confident about where I should be and where I would fit in the community.... And if you look at the way society looks at criminals and people who have lost their children, they don't think we're good people, they don't think we deserve any better than what we have or we don't deserve as much as they have. So that's [referring to her previous accommodation] where I thought society thought that I belonged. (Missie)

Missie's comments are demonstrative of the double stigma that comes with being a mother who has been incarcerated. They also suggest that even when there is an improvement in material conditions, stigma can still preclude women from feeling included.

Although feelings of stigma were quite real for women, some spoke about the perceived nature of stigma since it was something they carried internally. Liz spoke about how women tend to believe everyone knows their history even though this is often not the case: "Yeah, sometimes you feel like everybody knows even though nobody knows and nobody cares" (Liz). Missie described how a conversation with one of her supports helped her realize that despite how she feels she is perceived by others, most people in society cannot detect anything about her past when they meet her:

Well I mentioned to one of my supports that every time I went out I felt like I had "crack head" written on my forehead and that everyone knew I used to use crack and I was in prison. And she said, "You know, if I didn't meet you in prison I would never have thought that." That one thing she said changed my whole perspective. (Missie)

Bella reflected on the effect stigma has on women's feelings of acceptance and belonging. She concluded that while the stigma of incarceration is something that women carry inside, it is also something that exists in society:

Stigma is probably the biggest thing that's both something within you, like the fear within you of what people think of you but it's also a reality because people do think of you differently if they know. (Bella)

Bella's comments suggest that society has an understanding of what the label associated with incarceration means but not an understanding of the 
experiences of women who are connected with this label. When incarceration contributes to women being marked as different, there is greater propensity for exclusion, particularly when mutual identification with others hinges on totalizing notions of community. For example, as Young (1990) argued, "The most serious political consequence of the desire for community, or for co-presence and mutual identification with others is that it often operates to exclude or oppress those experienced as different (p. 234)."

The experiences of women in this study were in accordance with Young's critique. Exclusion appeared to be most pronounced for women when they viewed community as relatively homogenous and recognized the ways their social status and life experiences made them different and susceptible to stigmatization when opportunities for mutual identification were absent. This theme highlighted the ways women were pushed out and excluded from community. The next theme captures the ways women were pulled into community and the times they found inclusion from stabilizing supports and judgment-free spaces.

\section{Being Pulled Into Community: Finding Stabilizing Supports and Judgment-Free Spaces}

This theme captures the support women derived from groups, sponsors, volunteers, helping professionals, and reassuring family members. Women considered this social support essential for establishing connections in community. This theme also captures the comfort found in judgment-free spaces where women were not made to feel different from others in the community.

Bella highlighted the need for women entering community from prison to have people available and willing to welcome them:

We're talking about getting us involved in community. Well, the word community comes from the word communal-to share something. So it's not a community unless we're in it and we're sharing it with others. And we can't get into it unless we have people who are already on the inside pulling us into it, helping us. (Bella)

With this comment Bella acknowledged the sharing aspect of community and suggested that for community to be shared, people must help others be included.

Lucy explained that having a support group in the community was critical for helping her make the transition to community, particularly in the absence of family:

They drive me places if I need to go places, they do one-on-one counselling, they give me vitamins and bus tickets. They've just been there for me and I don't have family so having that has been huge. So my support group is something that I really leaned on. If I feel like putting a pipe to my lips I call them and they talk me out of it or they come and get me and we go for coffee. (Lucy) 
Being able to call people in a time of need helped Lucy manage her addiction. She admitted she would be struggling to be in community if it were not for her support: "If I didn't have the support I have, I don't know. I couldn't even imagine" (Lucy).

Sloan considered support from her Stride Circle $^{1}$ to be integral for helping her settle in a new area:

So I decided to come to Kitchener and I went into transitional housing. I had huge support from my Circle. I was new to this city and they helped me. They went above and beyond the call of duty. I reached out to people that would help me. (Sloan)

Missie also pointed to the need for women to have supports in community that extend beyond family. She presented a picture she had taken with her Stride Circle volunteer (not included here for purposes of confidentiality) and explained how this relationship helped her make inroads to finding employment:

[This picture] is of me and my Stride support. She is also my Christian mentor. I met her through a Chaplaincy program at GVI and then she took the Stride training so she could support me in the community and she's just been amazing. Since I'm struggling right now financially I made up a flyer to do some cleaning and she's given it out at church so I've gotten a couple of odd jobs that way.

(Missie)

Women described having access to various forms of social support pulling them into community when they were released from prison and they attributed this support to helping them feel included. Social support is often conceived as psychological and material resources intended to help people manage adversity and cope with stress (Cohen, 2004; Thoits, 1995). Researchers have often emphasized the importance of social support for women entering community. Richie, Freudenberg and Page (2001), for example, explained that social support is essential for providing women with the strength they need to resist being pulled toward substance abuse, familiar yet abusive relationships, and past criminal behaviours. Similar acknowledgement of the importance of support was made by women in this study when they explained how volunteers, family members, support groups and social groups were integral in helping them get re-established and resist the pull of addiction. Conversely, women are apt to feel alone when they enter community in the absence of family and community supports. Misha experienced loneliness during her transition phase and identified a need for women who have already transitioned to support other women entering community:

I think it would be great if women who come out and are successful could help other women come out and be successful. You know, give them information on housing and information on jobs, that kind of thing. Like a support group that meets once a month. When I came out I felt like I was totally alone and it would have been nice to have someone to talk to. (Misha) 
Pollack's (2009) research highlighted the importance of peer support and friendship for women who enter community after incarceration. She explained that when women get released from prison they are often unfamiliar with community resources, have difficulty forging new relationships, and ultimately feel disconnected and othered. Women in Pollack's study considered connecting with other women who shared the lived experience of a prison sentence imperative for minimizing feelings of isolation and stigma. While Misha identified a need for women who transitioned from prison to community to support others going through this phase, other women in the study indicated they preferred to distance themselves from women who have been in prison, opting instead to seek assistance from volunteers and support groups. These associations seemed to help women disconnect from the prison population and feel more connected with others in community.

Misha eventually found some of the support she needed to be pulled into community by joining a social group. She took a picture of women in her social group, The Red Hat Society, and explained, "(We are) women over fifty who want to get together. (We) wear red hats and purple outfits and we really don't give a shit what people think of us" (Misha).

While Misha joined the Red Hat Society to find connection in community, a reading of Goffman's (1963) work suggests she will not truly find belonging within this group. According to Goffman, people who are part of a stigmatized group can only be their authentic selves within this group. He further argued when a person is stigmatized, he or she can be part of other groups but can never really be considered as one of them. Not only does this idea offer little hope for women in this study to move beyond their criminalized identities and make meaningful connections with others in the community, it also suggests stigmatized individuals can be pulled so far into community but cannot truly belong. This idea also suggests that individuals and groups are stigmatized when community, holding to normative ideals, rejects difference.

The mission of the Red Hat Society emphasizes building relationships with other women and, beyond the requirement of being female; there are no restrictions on who can join (Son, Yarnal, \& Kersletter, 2010). Thus, it appears to be a group to which any woman can conceivably belong. It is also considered to be a group from which women can access social support in a non-judgmental environment (Son et al., 2010). However, a strict dress code and a busy social schedule would likely preclude women who are not financially well off and have other more pressing needs to attend to from either joining or feeling a sense of affiliation with other members.

The Red Hat Society is just one example of a group women may choose to join as a means of finding connection to people beyond their stigmatized group of formerly incarcerated women. Yet, if Goffman's (1963) argument holds true and women in this study can never truly belong to a group which does not share their experiences of stigma, it follows that women may continue to find themselves in superficial relationships where they find some form of social support but will unlikely feel any true sense of inclusion.

In addition to discussing relationships with people in community, women 
described their relationships to community spaces. They discussed the importance of having community spaces that were judgment free where people either did not know about their criminal past or, if they did know, treated them no differently than anyone else.

\section{Spaces that are judgment free and accepting of difference}

When describing her ideal community Lucy explained: "Feeling comfortable in your surroundings, non-judgmental, like, I'm not going to look down at the kid with the mohawk. Everyone is different and that's okay. It takes all different people to make a community" (Lucy). Liz and Karen also recognized the value in having organizations in community that are judgment free and make them feel comfortable. For example, Liz took a picture of a place in community where she attended a support program (see Figure 2) and described it as: "(one of the places) where I feel most welcome. They don't judge you" (Liz).

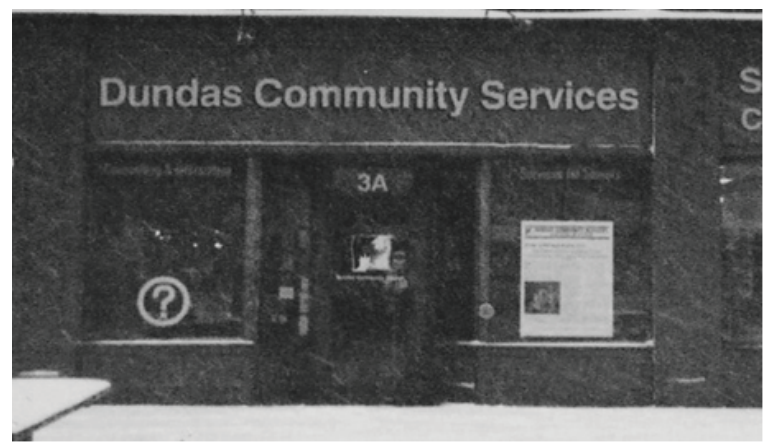

Figure 2

Tina spoke fondly of a place where she attended community support meetings because she considered it to be a place she could belong and not experience the stigma of incarceration: "This is where I go for my Home of the Heart meetings. They don't make you feel like you're a criminal. They're there to help no matter who you are" (Tina).

Women also expressed appreciation for public spaces in community where they were not made to feel any different than everyone else who used the services even when their history of incarceration was revealed. Liz took a picture of the library (see Figure 3) and explained she did not feel looked down on by library staff even though they could tell by the address on her library card that she lived in the halfway house:

Like going to the library, they know when you're from the halfway house but they don't treat you any different. I often have a problem with the machine to sign things out and when I tell them that they are right there to help just like I was somebody else. I don't feel looked down on when I'm there. (Liz) 


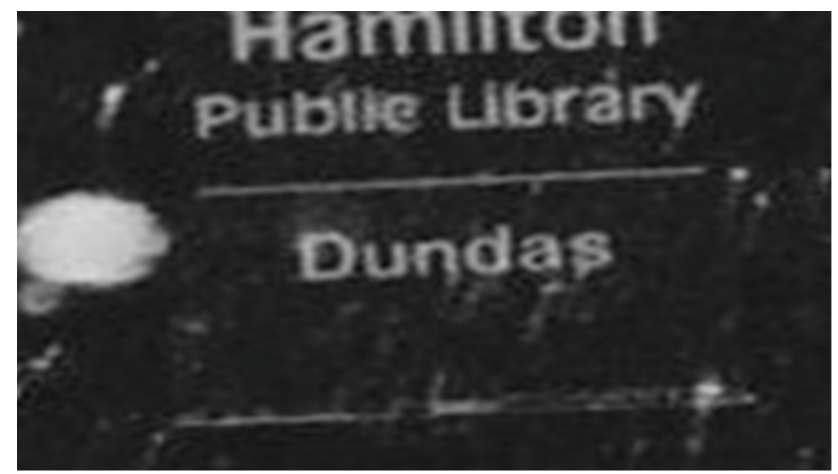

Figure 3

Similar to Liz's, Karen's view of acceptance was tied to the idea of not feeling judged. She explained she gets this kind of acceptance when she visits her mother in a nursing home: "I go visit my mom in the nursing home every day...I feel comfort there because they don't know (about my past) and they don't care. They don't look down on you. They just accept you for who you are" (Karen).

Nowell, Berkowitz, Deacon and Foster-Fishman (2006) found that the meanings assigned to community spaces can have substantive implications for individuals' sense of self and sense of belonging. As a departure from the ideal of community and its propensity for identifying with others based on commonality, being in judgment-free spaces where there is acceptance of difference seemed to remove pressure for women to conform to dominant expectations of behaviour in order to gain acceptance.

Block (2009) explained how a sense of belonging can occur when people have opportunities to connect with those who previously were strangers and relate in new ways across differences. Social differentiation without exclusion was possible in spaces where women felt they could be themselves, be anonymous, be different, just be. However, if judgment-free spaces are void of mutual connection, it raises doubt about the extent to which women will experience social inclusion in community. This idea is given further attention in the next theme as women discuss issues of responsibility in community entry as they relate to social inclusion and social justice.

\section{Negotiating Issues of Responsibility Pertaining to Social Inclusion}

This theme explores ideas about where responsibility should lie when it comes to social inclusion for women entering community from prison. Dominant discourse assumes that social inclusion for women who have been incarcerated means they must enter community as responsible citizens. Tensions are revealed in the way women think about responsibility as they waver between change as conformity and change as a process of mutual 
cooperation involving choice and support.

The idea that women should take sole responsibility for making changes in their lives after incarceration has been critiqued by Pollack (2007). She explained that a consequence of living in an individualistic society is that women who do not self-reform will be unlikely to experience social inclusion upon release from prison. Allspach (2010), Maidment (2006), and Pollack (2008) have all argued that notions of self-reform remain unchallenged as long as neo-liberal policies shape the way society responds to issues affecting citizens who are most marginalized.

\section{Change as conformity}

Women in this project identified things that needed to be changed when entering community and often suggested it was up to the individual to take responsibility to enact this change. Bella effectively captured women's proclivity for individual responsibility when she explained: "You gotta fall in line. So either you're in society or you're outside society" (Bella). Misha was also quick to acknowledge that if she wanted to be part of community she was the person responsible for making it happen:

I'm the one who has to make the step because for the longest time I sat home waiting to go out but being afraid that everybody knew what I did. You know, how do I explain where I've been? Now I'm more into going out and shedding that past so I'm more into my community now. (Misha)

During a conversation with Lucy and Bella, Lucy indicated that, despite changes needed in the environment into which women are entering, focusing solely on external factors undermines women's resiliency and capacity to redirect their lives away from crime:

Bella: Some people think the consequences aren't harsh enough to stop people from going out and committing crime. I don't think it's that the consequences aren't harsh enough; I think it's that the environment hasn't changed enough for these people to have a good reason not to commit crimes.

Lucy: Well we have a good reason not to so what's any different? It's because we want to change. I'm making myself have a good life. I want better for me. I want to end the cycle. My mother was the same-my mother was me. Her mother was her. I'm just stopping the cycle. I refuse to be the victim.

Lucy also argued that responsibility for self-reform should start while women are still incarcerated. She provided examples of opportunities available for women to improve themselves and suggested prison offers women a new start in life.

Lucy: Well, you know if you want to take that negative situation and let it be a negative situation or you can take that negative situation and turn it into a positive situation. Get your grade twelve, do all the courses, take the college 
courses that they offer and then become a better person. It's an opportunity to start clean with a fresh slate, right?

Researcher: So you think prison does work on some level?

Lucy: I think the two of us [referring to herself and Bella] are proof of that.

Women acknowledged that certain changes had to be made before women entering community could really belong. Changes identified were individual in nature and suggested a desire to conform to normative standards. For the most part, these changes pertained to the way women presented themselves in public. Bella, for example, described changes she felt she had to make pertaining to her manner of dress:

When I got arrested and I was on bail living with my mother, she said, "You can't continue to dress the way you dress. You have to start to dress like you're a member of society." I used to wear those baggy pants and I looked like a wannabe black boy. Over time I've come to terms with it but every now and then I still like to put on my comfortable clothes and I don't care what people think of me because I look good and I feel good. I had to change that to become a part of society and I had to look a certain way to fit in. (Bella)

Misha also explained that perception plays an important role in finding a job and emphasized this as an area where women need the most help to conform to society's expectations:

Maybe what has to be done is to go to the halfway houses and this is where you start teaching them how to do a resume, this is where you teach them time management, this is where you teach them how to dress for an interview so they're not going to an interview with their jeans hanging half way down their ass. So teach them etiquette because it's all about perception. That's how society works, it's all about perception. (Misha)

Misha viewed attempts to encourage society to be more caring and accepting of women who had been in prison as futile. In her view, effort should instead go toward changing women. She explained:

Well I think one of the things that has to be done is women have to lose their prison persona when they come out. You're not going to be able to change society's mind so you have to change the women. You know make them more approachable. I don't know what it is. Like people look at me and they don't think I've been in jail. People look at [name of another woman in the group] and they think she's been in jail. It's all about image. (Misha)

It is not surprising that women in this study bought into notions of individual responsibility since this idea is privileged in the correctional system. As Hannah-Moffat (2000) explained, Correctional Service of Canada's (CSC) rhetoric of shared responsibility and empowerment translates into female offenders being responsible for their own rehabilitation. The discourse of empowerment adopted by CSC highlights the need for changes in structural 
inequities experienced by female offenders and the need for changes in female offenders (TFFSW, 1990). Hannah-Moffat argued, however, that a model of empowerment for women who are federally incarcerated can be more aptly termed a model of individual responsibility. Empowerment is considered to be a process which supports women in gaining insight into their situation so they can take positive action to assume control over their lives. The state is no longer responsible for women's rehabilitation; rather, women are now expected to rehabilitate themselves (Hannah-Moffat, 2000). If a woman is not able to change her circumstances, it is believed she lacks the ability to make choices necessary to guide this transformation. Pollack (2004) has been quick to point out, however, that a lack of consideration is given to the idea that the same choices are not equally available to everyone.

\section{Individual responsibility for change versus cooperative approaches to change}

Conversations with women during this project largely focused on the ways they needed to change. Change was not often considered within the context of limited choices. Insufficient attention was also given to the ways community may need to cooperate with a woman's push for change and help to open up access to additional choices.

Missie stressed the role community ought to play in supporting women trying to make changes in their lives: "The community and people around us ought to help us make that change. If more community got involved in the transitional phase, accepting us and being more of a support" (Missie). Bella also emphasized the need for support to change but as her comments suggested, she felt conflicted about the extent to which this support is already available:

I think the person needs to change but society needs to give them opportunities to change. The problem is I want to say that but the reality is that there are so many opportunities out there, like free resume writing workshops, free social services. There is a place for everybody to go out and get support. I want to say that society needs to change but at the same time there is a lot of help available. (Bella)

Despite feeling ambiguous about the supports and choices they had available, women generally agreed that changes in public perception were needed when it came to women entering the community. These perceptual changes were deemed necessary to move closer to a community of acceptance and judgment-free space. Public awareness and knowledge were identified as necessary ingredients for change. As Karen explained, people's perceptions about women entering community might change if they had more knowledge: "We're not all bad people. So I think that stereotypes are something that I would like people to get knowledge about and maybe it would change their perception" (Karen). Similarly, Liz considered education and knowledge as 
necessary for curbing judgmental attitudes and behaviours toward women. She believed if people acquired knowledge, they may have a different point of view about people whom they would ordinarily judge as the other:

People who don't know and don't know what to expect will judge but if you give them knowledge and educate them they might start to look at it from a whole new perspective. You know, it's like now that I talked to you, now that I know you as a person, I might have a totally different outlook. So it's education and knowledge. (Liz)

Despite an expressed interest in bringing knowledge and awareness to the public, women also voiced some skepticism about how much potential there is to change societal perceptions of women entering community after incarceration. Misha, for example, spoke about people living with adversity who she felt would and should receive societal support before women who have spent time in prison:

Why should society support someone who is living off society when they can support a single mother who is out working and needs child care? Why should my money go toward that person instead of someone who needs it? My sympathies don't lie with-my sympathies don't even lie with myself. (Misha)

While Christie did not seem to believe such a community could exist, she described wanting to live in a community where there is shared responsibility among citizens, one in which there is equity in resources and support available to people facing adversity. For the community described by Christie to be a reality, deep-seated changes are needed at the societal level:

I don't know how this could be possible, but I'd also like a community with well-developed resources available to all for dealing with life's problems. I believe ending up in prison comes after a descent down a long slippery slope, and an ideal community would be able to intercede and help before things got bad with at least a large amount of the current incarcerated population. (Christie)

Women who participated in this study suggested that support from community may not always be forthcoming when it comes to helping address challenges women face as they leave prison and enter community. Some women spoke about not being able to find or access community resources they thought should be available to help them find connection to community. Other women questioned whether people in the community would or should care about women getting out of prison and speculated about where the responsibility lay when it came to women getting re-established in their postprison lives. Christie's comments about prison being the end of a descent down a slippery slope, which signifies community's failure to intervene earlier, highlighted the sheer absence of support available in community before a woman enters prison.

The breakdown of community resources for women who go to prison is a trend that can be seen elsewhere in the literature. Women who participated in Pollack's (2008) study, for example, referred to situations where they felt 
their communities had failed them before they entered prison. Indications of inadequate levels of community support for women who end up in prison can also be observed in the overreliance on the penal system to manage social problems (Wacquant, 2001). Wacquant referred to the international trend of prisons for women becoming prisons of poverty since persistent cycles of poverty and dependence are often precursors to women entering the prison system.

Women in this study expressed ambivalence regarding where responsibility lay when it came to a woman being included in community. They held two opposing beliefs: women leaving prison should be ultimately responsible for making personal changes that contribute to their inclusion, and, also, women could not do it alone. Recognition was given to the notion of an ideal community where, as Christie described, there is shared responsibility among citizens; a community in which there is equity in resources and support available for people in the face of adversity. For this ideal community to be a reality, a shift is needed, away from individualism, and toward a more socially just society.

\section{Discussion: A Shift Away from Individual Responsibility and Movement Toward Social Justice}

Women in this study realized they were culpable for offenses that brought them to prison and expressed the desire to make positive changes in their post-prison lives. At times they conveyed a sense of powerlessness and desperation in the face of such overwhelming life challenges. Exposing their vulnerabilities, some women held fast to a belief that members of the community were an integral part of their quest for change. Other women held firm to the belief that women leaving prison should be solely responsible for making personal changes that would ultimately contribute to their inclusion.

As women negotiated issues of responsibility, there was an underlying tension around whether social inclusion and subsequent movement toward social justice could ever be a reality. Indeed the idealized community and its assurance of inclusion may seem like a fabrication for individuals who have broken the law (Pedlar et al., 2008; Pollack, 2008). As Foucault (1975) pointed out, the act of breaking the law means the criminal is seen as having offended all of society and must be punished so society may obtain retribution for the crime. The resulting exclusion can be difficult to overcome.

The challenge of overcoming exclusion associated with offending society is most evident in the dominant language around notions of selfreform and "redeemability" (Maruna \& King, 2009). Uncritical acceptance of reformation and redemption suggests that individuals who have been convicted of crimes are in a constant state of flux where their acceptance is always impermanent and fragile. Worrall (1997) emphasizes the fragility of inclusion for individuals who break the law and provides a glimpse at the direction Canada could be heading if we continue to enact punitive and 
exclusionary policies such as Bill C-10:

While the term [community] may appeal to a warm, nostalgic sense of "belonging" among the self-proclaimed law-abiding citizen, its promise of inclusivity can be interpreted in contradictory ways when applied to those who break the law and are criminalized. Far from demonstrating that it is resourceful, tolerant, and healing, the community is then rejecting, excluding and intolerantly punitive. (Worrall, 1997, p. 47)

If we view inclusion and belonging as a goal of social justice, we begin to see the ways shared responsibility and mutuality are necessary for women to be included in community. Reid (2004) explained, "[social] injustice is how people are excluded, the depths to which they suffer, and the obligations we bear in this regard" (p. 245). From this statement we can infer that social justice is how people are included and the obligations we also bear in this regard.

Inclusion for women who have offended may seem unconscionable in a society that prides itself on the strengths of individualism and an ability to overcome adversity. However, crime does not occur in a vacuum (Fortune, Pedlar, \& Yuen, 2010). Rather, as Christie previously described, crime usually arises out of social conditions fostered in society. Thus, it seems a society that accepts and nurtures these conditions ought to share part of the responsibility for the adverse effects created and help to take steps that lead to social change. It was this very notion that prompted the TFFSW (1990) to incorporate the principle of shared responsibility into Creating Choices when it considered the changes that needed to be made to women's corrections.

Women in this study recognized the need to make changes in their lives. After enduring years of social and personal betrayal within community (Fine et al., 2004), they predictably found it difficult to accept that community suddenly had a role to play in supporting these changes. However, if we admit to social injustices being present in our society and we embrace the hope that comes in the form of messages encouraging social change (e.g., Layton, 2011), we must also admit that inclusion, as a measure of social justice, is a social and therefore shared responsibility and its full expression requires a shift to mutuality in our relationships and understandings.

\section{Conclusion: A New Vision of Inclusion that Values Difference and Encourages Mutuality}

Women who participated in this research project were diverse and had varied experiences prior to their incarceration and when entering community. Yet, feelings of exclusion were common as they spoke of entering community with insufficient support networks, resources, and acceptance from others. They articulated how the stigma of being an offender tends to persist long after a prison sentence is complete and can impact the extent to which they feel connected to community upon release. Women in this study had a heightened 
awareness of their culpability for offenses that brought them to prison and expressed wanting to make positive changes in their post-prison lives that would enhance their feelings of inclusion. Importantly however, embedded within their views of inclusion were distinctions between the choice to make change and conformity.

The element of choice was inherent in the descriptions of the ways they embraced change on their own terms. Being with people who accepted them and supported their efforts to change and spending time in spaces where they felt accepted and free from judgment not only augmented their efforts but also started to set the stage for inclusion and belonging. When conformity was at the forefront of discussion, women perpetuated the belief that difference is antithetical to inclusion and social inclusion will remain an aberration for individuals who do not adhere to dominant societal expectations.

Many issues raised throughout this study are specific to women who are entering community after incarceration. The deep exclusion experienced by people placed outside community and sent to prison is arguably unparalleled and women who spend time in prison are particularly susceptible to exclusion. However, this project is ultimately concerned with society's tendency to exclude people based on a devaluation of difference. Exclusion is an inevitable outcome when differences are viewed as problems to solve (Block, 2009). We take steps toward inclusion when we view difference as sources of community vitality and hold ourselves accountable for the wellbeing of others in community (Block, 2009).

Women in this research project often found it difficult to look beyond notions of self-reform and therefore searched for acceptance and inclusion by trying to adopt pro-social identities. Such personal changes placed each individual woman at the centre of the solution to social problems related to exclusion. However, an anti-oppressive view of social inclusion that is also socially just would take into consideration that both structural determinants and individual agency lie at the heart of inclusion processes (Dominelli, 2005; Lister, 2000). When it comes to achieving inclusion, Sin and Chung Yan (2003) assert that "the challenge for society is how to share power, relegate privileges, and give space for people at the margins to define and locate the centre as a strategy of anti-oppressive struggles" (p. 33). In this sense the margins can be sites for resistance and creative spaces that encourage new perspectives.

Some women who participated in this project took pictures indicating they valued spaces in community where their differences did not impact how they were treated by others. With their pictures they suggested they did not necessarily want to move from the margin to the centre by conforming to mainstream society and pretending differences did not exist. Rather, inclusion was about the creation of a space where people who are different from mainstream society are not made to feel inferior. When women in this study felt free to participate in the life of their community in ways that did not undermine their sense of self and their differences, they were in the process of being included. Findings from this study suggest we need to be better at 
creating space for difference and social inclusion to co-exist.

Johnson (2006) wrote that, "reducing people to a single dimension of who they are separates and excludes them, marks them as 'other,' as different from 'normal' (white, heterosexual, male, nondisabled) people and therefore as inferior" (p. 19). Johnson also explained that exclusion inevitably results when differences that have no inherent connection to social inequality are seized on and become a basis for oppression. Women were asked to participate in this research project because they had spent time in prison. Beyond that, however, they were not homogeneous and varied with respect to many aspects of their identity, such as social class, race, and sexual orientation. Yet, there was a common experience of exclusion linked to their incarceration as well as the ways their experiences before and after incarceration marked them as different from an assumed norm. Incarceration has very real implications for social inclusion that is tied to ongoing social control and marginality and this has been found to be particularly the case for women (Allspach, 2010). However, as this research showed, even if women do not explicitly identify with being marginalized due to practices of social control after their release from prison, the extent to which they are included in community can be jeopardized by idealized notions of community and their experiences of difference.

For women to be in community (as opposed to prison), change is needed in terms of desistance from criminal activity. Given the multifaceted nature of criminal activity, this type of change may not be simple or straightforward. However, for women to be included in community after release from prison, dynamics surrounding change can be even more complex. When women believe they need to change fundamental aspects of who they are in order to be valued and accepted by others, there is reason to be critical of the ways that social inclusion can undermine difference. Similarly, when women's quests for personal change and growth are dependent on the extent to which there is support and shared responsibility for addressing the issues of inequality they are faced with, there is reason to advocate for social inclusion as an aspect of social justice. This research suggests a need for social change and identifies the role of community in supporting personal change and growth. It is imperative that community not only collectively strive to diminish social inequalities, but accept difference without trying to change it and understand that people's limitations are intertwined with their gifts (McKnight \& Block, 2012). In practical terms, this would translate to actions that involve advocating for movement away from punitive and exclusionary policies toward policies and programs that are socially just. It would also involve each of us embracing our mutual obligation for the well-being of others and engaging in dialogue aimed at creating space that is hopeful and inclusive for all citizens. After all, as Canadians, this is the hopeful space we are longing for.

\section{Acknowledgements}

We wish to thank the women who participated in this research project. Your 
willingness to share your insights and experiences and engage in critical and sometimes difficult discussions is very much appreciated. This work would not have been possible without you.

\section{Notes}

1 The Stride Circle program is available to women at Grand Valley Institution for Women in Kitchener, Ontario. It is a program facilitated by Community Justice Initiatives, an agency founded on principles of restorative justice. A Stride Circle is typically comprised of a woman who is seeking support as she transitions from prison to community and two or three trained community volunteers who care about her and want to be part of this journey.

\section{References}

Allspach, A. (2011). Landscapes of (neo)-liberal control: The transcarceral spaces of federally sentenced women in Canada. Gender, Place and Culture, 17(6), 705-723.

Bach, M., \& Rioux, M.H. (1996). Social well-being: A framework for quality of life research. In R. Renwick, I. Brown, \& M. Nagler (Eds.), Quality of life in health promotion and rehabilitation (pp. 63-74). Thousand Oaks: Sage Publications.

Bauman, Z. (2001). Community: Seeking safety in an insecure world. Cambridge, UK: Polity Press.

Baumeister, R.F., \& Leary, M.R. (1995). The need to belong: Desire for interpersonal attachments as a fundamental human motivation. Psychological Bulletin, 117(3), 497-529.

Bell, L.A. (1997). Theoretical foundations for social justice education. In M. Adams, L.A. Bell, \& P. Griffin (Eds.), Teaching for diversity and social justice (pp. 3-15). New York, NY: Routledge.

Block, P. (2009). Community: The Structure of Belonging. San Francisco: Berrett-Koehler Publishers, Inc.

Barnett, L. Dupuis, T, Kirkby, C., MacKay, R. Nicol, J., Legal and Legislative Affairs Division, Julie Béchard, Social Affairs Division (2012). Legislative Summary of Bill C-10: An Act to enact the Justice for Victims of Terrorism Act and to amend the State Immunity Act, the Criminal Code, the Controlled Drugs and Substances Act, the Corrections and Conditional Release Act, the Youth Criminal Justice Act, the Immigration and Refugee Protection Act and other Acts. Parliamentary Library Research Publications. Retrieved from http://www.parl. gc.ca/About/Parliament/LegislativeSummaries/bills_ls.asp?Language $=E \& 1 \mathrm{~s}=\mathrm{c} 10 \& \mathrm{Parl}=41$ $\&$ Ses $=1 \&$ source $=$ library_prb

Cohen, S. (2004). Social relationships and health. American Psychologist, November 2004, 676-684.

Dominelli, L. (2005). Social inclusion in research: Reflecting on a research project involving young mothers in care. International Journal of Social Welfare, 14, 13-22.

Faith, K. (2006). 13 women: Parables from prison. Vancouver, BC: Douglas \& MacIntyre.

Fine, M., Torre, M.E., Boudin, K., Bowen, I., Clark, J., Hylton, D., ...Upegui, D. (2004). Participatory action research: From within and beyond prison bars. In L. Weis \& M. Fine (Eds.), Working method: Research and social justice (pp. 173-198). New York: Routledge.

Fortune, D., Pedlar, A., \& Yuen, F. (2010). Leisure and social development in the context of women who offend. In H. Mair, S.M. Arai, \& D.G. Reid (Eds.), Decentring work: Critical perspectives on leisure, development, and social change (pp. 175-202). Calgary, AB: University of Calgary Press.

Foucault, M. (1975). Discipline and punish: The birth of the prison. New York: Random House.

Frazer, E., \& Lacey, N. (1993). The politics of community: A feminist critique of the liberalcommunitarian debate. Toronto, ON: University of Toronto.

Frisby, W., Reid, C., Millar, S., \& Hoeber, L. (2005). Putting "participatory" into participatory forms of action research. Journal of Sport Management, 19(1), 367-396.

Giroday, G. (2011). Crime bill unfairly targets women, aboriginals, critics say. Winnipeg Free Press. 
Goffman, E. (1963). Stigma: Notes on the management of spoiled identity. Englewood Cliffs, N.J.: Prentice-Hall.

Hall, E. (2005). The entangled geographies of social exclusion/inclusion for people with learning disabilities. Health \& Place, 11, 107-115.

Hannah-Moffat, K. (2000). Reforming the prison: Rethinking our ideals. In K. Hannah-Moffat \& M. Shaw (Eds.), An ideal prison? Critical essays on women's imprisonment in Canada (pp. 30-40). Halifax, NS: Fernwood Publishing.

Himelfarb, A. (2011). The Omnibus Bill: Is it getting tough on crime, or getting tough on the poor? The CCPA Monitor, 18(3).

Johnson, A.G. (2006). Privilege, power, and difference $\left(2^{\text {nd }} E d\right)$. New York: McGraw Hill.

Labonte, R. (2004). Social inclusion/exclusion: Dancing the dialectic. Health Promotion International, 19(1), 115-121.

Laidlaw Foundation. (2002). Working papers: Perspectives on social inclusion. Toronto, ON: Author.

Layton, J. (2011, August). Jack Layton's last letter to Canadians. Retrieved from http://www. cbc.ca/news/politics/story/2011/08/22/pol-layton-last-letter.html

Lister, R. (2000). Strategies for social inclusion: Promoting social cohesion or social justice. In P. Askonas \& A. Stewart (Eds.), Social inclusion: Possibilities and tensions (pp. 37-54). New York, NY: St. Martin's Press.

Maidment, M.R. (2006). Doing time on the outside: Deconstructing the benevolent community. Toronto, ON: University of Toronto Press.

Maruna, S., \& King, A. (2009). Once a criminal, always a criminal?: "Redeemability" and the psychology of punitive public attitudes. European Journal on Criminal Policy and Research, $15,7-24$.

MacDonald, M., Sarche, J., \& Wang, C.C. (2005). Using the arts in community organizing and community building. In M. Minkler (Ed.), Community organizing and community building for health (pp. 346-363). New Brunswick, NJ: Rutgers University Press.

McKnight, J. \& Block, P. (2012). The abundant community: Awakening the power of families and neighborhoods. San Francisco: Berrett-Koehler Publishers.

Mitchell, A., \& Shillington, R. (2005). Poverty, inequality and social inclusion. In T. Richmond \& A. Saloojee (Eds.), Social inclusion: Canadian perspectives (pp. 33-57). Halifax, NS: Fernwood Publishing.

Moosa-Mitha, M. (2005a). A difference-centred alternative to theorization of children's citizenship rights. Citizenship Studies, 9(4), 369-388

Moosa-Mitha, M. (2005b). Situating anti-oppressive theories within critical and differencecentered perspectives. In L. Brown \& S. Strega (Eds.), Research as resistance: Critical, indigenous, and anti-oppressive approaches (pp. 37-72). Toronto, ON: Canadian Scholar's Press/Women's Press.

Nowell, B. L., Berkowitz, S.L., Deacon, Z., \& Foster-Fishman, P. (2006). Revealing the cues within community places: Stories of identity, history, and possibility. American Journal of Community Psychology, 3(1/2), 29-46.

Pedlar, A., Arai, S., \& Yuen, F. (2007). Media representations of federally sentenced women and leisure opportunities: Ramifications for social inclusion. Leisure/Loisir, 3(1), 255-276.

Pedlar, A., Arai, S., Yuen, F., \& Fortune, D. (2008). Uncertain futures: Women leaving prison and re-entering community. Retrieved from http://www.ahs.uwaterloo.ca/uncertainfutures/

Pollack, S. (2004). Anti-oppressive social work practice with women in prison: Discursive reconstructions and alternative practices. British Journal of Social Work, 34(5), 693-707.

Pollack, S. (2007). "I'm just not good in relationships": Victimization discourses and the gendered regulation of criminalized women. Feminist Criminology, 2(2), 158-173.

Pollack, S. (2008). Locked in, locked out: Imprisoning women in the shrinking and punitive welfare state. Retrieved from http://www.flintbox.com/technology.asp?page $=3420$

Pollack, S. (2009). "Circuits of exclusion": Criminalized women's negotiation of community. Canadian Journal of Mental Health, 28(1), 83-95.

Potts, K., \& Brown, L. (2005). Becoming an anti-oppressive researcher. In L. Brown \& S. Strega (Eds.), Research as resistance: Critical, indigenous, and anti-oppressive approaches (pp. 255-286). Toronto, ON: Canadian Scholar's Press/Women's Press.

Radosh, K. (2002). Reflections on women's crime and mothers in prison: A peacemaking approach. Crime and Delinquency, 48(2), 300-315. 
Reid, C. (2004). The wounds of exclusion: Poverty, women's health \& social justice. Edmonton, AB: Qualitative Institute Press.

Reid, C., \& Frisby, W. (2008). Continuing the journey: Articulating dimensions of feminist participatory action research (FPAR). In P. Reason \& H. Bradbury (Eds.), Sage handbook of action research: Participative inquiry and practice ( $2^{\text {nd }}$ ed.) (pp. 93-105). London: Sage Publications.

Richie, B.E. (2001). Challenges incarcerated women face as they return to their communities: Findings from life history interviews. Crime and Delinquency, 47(3), 368-389.

Richie, B., Freudenberg, N., \& Page, J. (2001). Reintegrating women leaving jail into urban communities: A description of a model program. Journal of Urban Health, 78(2), 290-303.

Rose, N. (2000). Government and control. British Journal of Criminology, 40, 321-339.

Ruddell, R., \& Winfree, L.T. (2006). Setting aside criminal convictions in Canada: A successful approach to offender reintegration. The Prison Journal, 86(4), 452-469.

Saloojee, A. (2005). Social inclusion, anti-racism and democratic citizenship. In T. Richmond \& A. Saloojee (Eds.), Social inclusion: Canadian perspectives (pp. 180-202). Halifax, NS: Fernwood Publishing.

Shakir, U. (2005). Dangers of a new dogma: Social inclusion or else . . . ! In T. Richmond \& A. Saloojee (Eds.), Social inclusion: Canadian perspectives (pp. 203-214). Halifax, NS: Fernwood Publishing.

Shookner, M. (2002). An inclusion lens: Workbook for looking at social and economic exclusion and inclusion. Halifax, NS: Population and Public Health Branch Atlantic Region.

Siegal, J.A. (2011). Disrupted Childhoods: Children of Women in Prison. New Jersey: Rutgers University Press.

Sin, R., \& Chung Yan, M. (2003). Margins as centres: A theory of social inclusion in antioppressive social work. In W. Shera (Ed.), Emerging perspectives on anti-oppressive practice (pp. 25-41). Toronto, ON: Canadian Scholar's Press Inc.

Son, J., Yarnal, C., Kerstetter. D. (2010). Engendering social capital through a leisure club for middle-aged and older women: Implications for individual and community health and wellbeing. Leisure Studies, 29(1), 67-83.

Taket, A., Crisp, B. R., Nevill, A., Lamaro, G., Graham, M., \& Barter-Godfrey, S. (2009). Theorising social exclusion. New York, NY: Routledge.

Task Force on Federally Sentenced Women (TFFSW). (1990). Creating choices: The report of the Task Force on Federally Sentenced Women. Ottawa, ON: Solicitor General of Canada.

Taylor, K., \& Flight, J. (2004). A profile of federally-sentenced women on conditional release. Forum on Corrections Research, 16, 24-27.

Thoits, P.A. (1995). Stress, coping, and social support processes: Where are we? What next? Journal of Health and Social Behavior, 35, 53-79.

Uggen, C., Manza, J., \& Behrens, A. (2004). 'Less than the average citizen': Stigma, role transition and the civic reintegration of convicted felons. In S. Maruna \& R. Immarigeon, (Eds.), After crime and punishment: Pathways to offender reintegration (pp. 258-290). Cullompton, Devon, UK: Willan.

Wang, C., \& Burris, M.A. (1997). Photovoice: Concept, methodology and use for participatory needs assessment. Health Education and Behaviour, 24(3), 369-387.

Wilkinson, R., \& Marmot, M. (Eds.). (2003). Social determinants of health: The solid facts (2nd ed.). New York, NY: World Health Organization.

Worrall, A. (1997). Punishment in the community: The future of criminal justice. London: Longman.

Young, I. M. (1989). Polity and group difference: A critique of the ideal of universal citizenship. Ethics, 99(2), 250-274.

Young, I. M. (1990). Justice and the politics of difference. Princeton, NJ: Princeton University Press. 